\title{
Role of advanced neuroimaging, fluid biomarkers and genetic testing in the assessment of sport-related concussion: a systematic review
}

\author{
Michael McCrea, ${ }_{1}^{1}$ Timothy Meier, ${ }^{1,2}$ Daniel Huber, ${ }^{1}$ Alain Ptito, ${ }^{3,4}$ Erin Bigler, ${ }^{5}$ \\ Chantel T Debert, ${ }^{6}$ Geoff Manley ${ }^{7}$ David Menon, ${ }^{8}$ Jen-Kai Chen, ${ }^{9}$ Rachel Wall, ${ }^{10}$ \\ Kathryn J Schneider, ${ }^{11}$ Thomas McAllister $^{10}$
}

- Additional material is published online only. To view please visit the journal online (http://dx.doi.org/10.1136/ bjsports-2016-097447).

For numbered affiliations see end of article.

\section{Correspondence to}

Dr Michael McCrea, Department of Neurosurgery, Medical College of Wisconsin, 9200 W. Wisconsin Avenue, Milwaukee 53226, Wisconsin, USA: mmccrea@mcw.edu

Accepted 2 March 2017 Published Online First 7 March 2017
ABSTRACT

Objective To conduct a systematic review of published literature on advanced neuroimaging, fluid biomarkers and genetic testing in the assessment of sport-related concussion (SRC).

Data sources Computerised searches of Medline, PubMed, Cumulative Index to Nursing and Allied Health Literature (CINAHL), PsycINFO, Scopus and Cochrane Library from 1 January 2000 to 31 December 2016 were done. There were 3222 articles identified.

Study selection In addition to medical subject heading terms, a study was included if (1) published in English, (2) represented original research, (3) involved human research, (4) pertained to SRC and (5) involved data from neuroimaging, fluid biomarkers or genetic testing collected within 6 months of injury. Ninety-eight studies qualified for review (76 neuroimaging, 16 biomarkers and 6 genetic testing).

Data extraction Separate reviews were conducted for neuroimaging, biomarkers and genetic testing. A standardised data extraction tool was used to document study design, population, tests employed and key findings. Reviewers used a modified quality assessment of studies of diagnostic accuracy studies (QUADAS-2) tool to rate the risk of bias, and a modified Grading of Recommendations Assessment, Development, and Evaluation (GRADE) system to rate the overall level of evidence for each search.

Data synthesis Results from the three respective reviews are compiled in separate tables and an interpretive summary of the findings is provided.

Conclusions Advanced neuroimaging, fluid biomarkers and genetic testing are important research tools, but require further validation to determine their ultimate clinical utility in the evaluation of SRC. Future research efforts should address current gaps that limit clinical translation. Ultimately, research on neurobiological and genetic aspects of SRC is predicted to have major translational significance to evidence-based approaches to clinical management of SRC, much like applied clinical research has had over the past 20 years.

\section{INTRODUCTION}

CrossMark

To cite: McCrea M, Meier T, Huber D, et al. Br I Sports Med 2017:51:919-929.
Over the past decade, there has been major progress in the methods for evaluation of sport-related concussion (SRC) and in determining the natural history of clinical recovery after injury. ${ }^{1-4}$ Critical questions remain, however, about the acute neurobiological effects of SRC on brain structure and function, and the eventual time course of physiological recovery after injury.

Studies using advanced neuroimaging techniques have demonstrated that concussion is associated with metabolic and physiological changes in the brain, which correlate with postconcussive symptoms and performance on neurocognitive testing during the acute postinjury phase. ${ }^{5-12}$ In parallel, the assessment of novel and selective blood biomarkers and genetic testing for traumatic brain injury (TBI) has rapidly expanded, but with limited application to the study of SRC. Extending from the broader TBI literature, there is also increasing interest in the role of genetics in predicting risk of injury, prolonged recovery and long-term neurological health problems associated with SRC and repetitive head impact exposure in athletes. ${ }^{13}$

Clinically, there is a need for diagnostic biomarkers as a more objective means to assess the presence/ severity of concussion in athletes. Beyond the potential diagnostic utility, there is also keen interest in the development of prognostic biomarkers of recovery after SRC. Emerging data suggest that physiological abnormalities may persist beyond the typical window of clinical recovery after mild traumatic brain injury (mTBI), which raises concerns about risks associated with repeat injury during the acute recovery phase. ${ }^{14}$

15 Most concerning is that a window of cerebral vulnerability may extend beyond the point of clinical recovery, when the brain remains physiologically compromised and athletes are at heightened risk of repetitive injury. Imaging and blood biomarkers that reliably reflect the extent of neuronal, axonal and glial damage and/or microscopic pathology could conceivably diagnose and predict clinical recovery outcome after SRC.

We conducted a systematic review of the existing literature on the utility of advanced imaging, fluid biomarkers and genetic testing in the assessment of SRC.

\section{METHODS}

Systematic review methodology ${ }^{16}$ was employed to address the following core questions for the 5 th International Consensus Conference on Concussion in Sport:

- What advanced or novel tests can assist in the assessment of SRC?

- What is the role for advanced neuroimaging?

- What is the role for cerebral spinal fluid (CSF), blood, and urine and saliva biomarkers? 
Table 1 Medical subject heading terms and key words used for electronic database searches

(Concussion OR concuss* OR brain injuries OR head injuries OR ((head OR brain) AND injur*) OR Post-Concussion Syndrome OR postconcussion* OR Mild traumatic brain injury OR MTBI OR acquired brain injury OR blunt head trauma OR Craniocerebral Trauma OR (('mild traumatic' OR acquired) AND brain injur*)) AND (athletes OR sports OR sport OR sporting $O R$ athleti* $O R$ athlete* $O R$ recreation $O R$ recreat* $O R$ baseball $O R$ bicycling $O R$ boxing $O R$ cycling $O R$ diving OR equestrian OR equine OR football OR Head Protective Devices OR helmet* OR hockey OR lacrosse OR martial arts $O R$ karate $O R$ judo $O R$ tae kwon do $O R$ aikido $O R$ mountaineering $O R$ racquet sports $O R$ rugby $O R$ skating $O R$ skiing $O R$ snow sports OR soccer OR wrestling)

\begin{tabular}{|c|c|c|c|}
\hline Head injury and relevant sports. & Neuroimaging search & Biomarkers search & Genetics search \\
\hline Advanced or novel tests & $\begin{array}{l}\text { (Neuroimaging OR radiological OR } \\
\text { neuroradiological OR brain imaging } \\
\text { OR Positron-Emission Tomography OR } \\
\text { ((PET OR MRI) AND (scan OR scans)) } \\
\text { OR Magnetic Resonance Imaging OR } \\
\text { ((structural OR Functional) AND MRI) OR } \\
\text { spectroscopy OR Magnetic Resonance } \\
\text { Spectroscopy OR Diffusion Tensor } \\
\text { Imaging OR Arterial Spin Labeling OR } \\
\text { Electroencephalography OR EEG OR } \\
\text { Diagnostic Techniques, Neurological } \\
\text { OR Magnetoencephalography OR } \\
\text { Fluid-attenuated inversion recovery OR } \\
\text { Diagnostic imaging OR Quantitative EEG } \\
\text { OR QEEG OR event-related potentials } \\
\text { OR 'event related potential*' OR 'evoked } \\
\text { potential' OR ERP OR scanning OR fMRI } \\
\text { OR 'resting-state' OR 'resting state') }\end{array}$ & $\begin{array}{l}\text { (Biomarkers OR biomarker OR } \\
\text { neuroendocrine OR pituitary OR } \\
\text { hormone* OR cortisol OR hydrocortisone } \\
\text { OR gonadal steroid hormones OR } \\
\text { growth hormone OR thyroid OR SIADH } \\
\text { OR Inappropriate ADH Syndrome OR } \\
\text { ((Cerebrospinal OR 'cerebro spinal') } \\
\text { AND fluid*) OR CSF OR Serum OR } \\
\text { urine OR saliva OR neuronal OR glial } \\
\text { OR neuroglia OR axonal OR (Marker* } \\
\text { AND (immunologic OR laboratory OR } \\
\text { clinical OR biochemical OR immune OR } \\
\text { immunologic OR biological OR biologic))) }\end{array}$ & $\begin{array}{l}\text { (Epigenetic* OR Epigenomics OR 'copy } \\
\text { number' OR 'rare variant }{ }^{* \prime} \text { OR Genetic } \\
\text { Variation OR 'genetic diversit*' OR } \\
\text { genotype OR genogroup* OR genotype* } \\
\text { OR genetics OR genetic* OR mitochondria } \\
\text { OR mitochond* OR Intracellular signaling } \\
\text { peptides and proteins OR Polymorphism, } \\
\text { Genetic OR DNA Copy Number } \\
\text { Variations OR 'DNA polymorphism' OR } \\
\text { 'genotype environment interaction' OR } \\
\text { Polymorphism, Single Nucleotide OR } \\
\text { 'Intracellular signaling' OR genome OR } \\
\text { OR genomics OR genom* OR allele OR } \\
\text { allel* OR chromosomes OR chromosom* } \\
\text { OR 'genetic testing') }\end{array}$ \\
\hline
\end{tabular}

- What is the role for genetic or epigenetic testing?

Three separate systematic literature searches (neuroimaging, biomarkers and genetics) were conducted to address each of the outlined questions above. The stepwise approach and workflow for our systematic searches were registered with an international prospective register of systematic reviews ${ }^{17}$ (see online supplementary appendices $1-3$ ). Prior reviews have separately evaluated the state of the science on imaging, biomarkers and genetics in the broader spectrum of TBI or SRC, ${ }^{18-22}$ but this is the first integrated review of the most up-to-date evidence on these novel technologies specific to SRC.

\section{Databases and search terms}

Our literature search used PubMed/Medline, Scopus, Cumulative Index to Nursing and Allied Health Literature (CINAHL), PsycINFO and Cochrane Library. Given the focus of this systematic review on the evolution of emerging technologies, our search was limited to the published literature from 1 January 2000 to 31 December 2016. The decision to include published literature dating back to 2000 was based on the relevance of modern technologies to our specific review question; this approach is further supported by the finding that the earliest publication of articles meeting our inclusion criteria was 2004 for MRI, 2013 for biomarkers and 2015 for genetics. The search strategy was developed in conjunction with an expert medical librarian, who also conducted an independent peer review of the strategy. Table 1 summarises the combination of key words and medical subject headings (MeSH) terms used for the three respective searches. A common group of search terms for head injury and sport was used for all three searches, then combined with the specific terms for searches related to neuroimaging, biomarkers and genetics.

\section{Study selection criteria}

In addition to meeting the $\mathrm{MeSH}$ term criteria, the basic requirements for a study to be included in our search were that the article (1) was published in English, (2) represented original research, (3) involved human research, (4) pertained only to SRC (ie, not non-sports TBI), (5) included data from studies involving neuroimaging (including electrophysiological testing), fluid biomarkers or genetic testing in the assessment of SRC, and (6) had at least one data collection point within 6 months of injury. Two reviewers collaboratively screened articles for inclusion. Titles and abstracts were reviewed first, and duplicates and irrelevant articles were excluded, followed by full-text screenings. A third reviewer was consulted to resolve discrepancies about article inclusion.

\section{Data extraction and analysis}

Members of the author group extracted relevant data from included studies to populate the data extraction tool for each search. The author group then conducted reviews relevant to each search based on their respective area of subject matter expertise (neuroimaging, biomarkers and genetics). For the included studies, a standardised data extraction method was used (see tables 2-4 for the data extraction tools for the neuroimaging, biomarker and genetic searches). Articles are listed in chronological order based on publication year to illustrate the pattern and evolution of research over time. Two subject matter experts from our working group independently examined all retrieved citations to determine eligibility for inclusion.

\section{Assessment of risk of bias and level of evidence}

As recommended by the Cochrane Collaboration, a modified version of the QUADAS-2 was used to assess the risk of bias for identified diagnostic accuracy studies ${ }^{23}$ (see online supplementary appendix 1). Generalisability was assessed based on the degree of representativeness across age, gender and sport. Two primary reviewers for each study independently assessed the risk of bias in identified studies. Using the modified QUADAS-2 tool, the overall risk of bias was assessed (low, moderate and high) for each included study. Discrepancies were resolved by consensus after consulting with an independent third rater. 


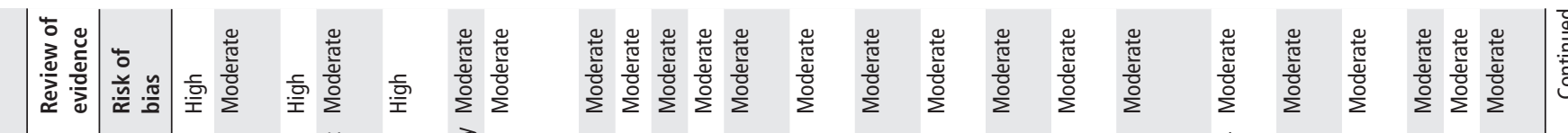

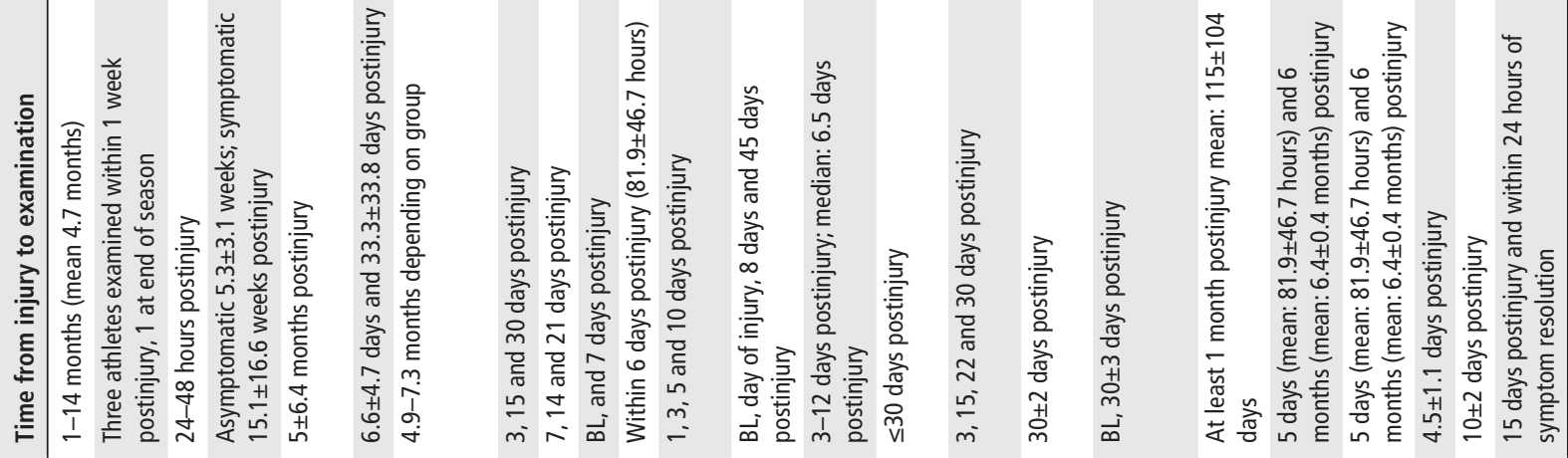

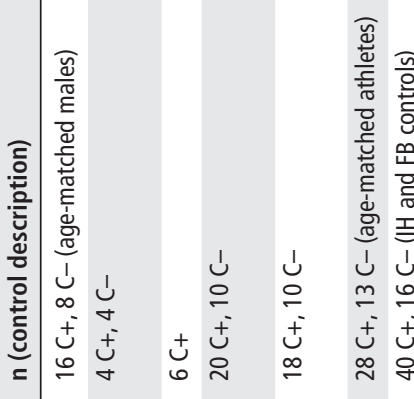

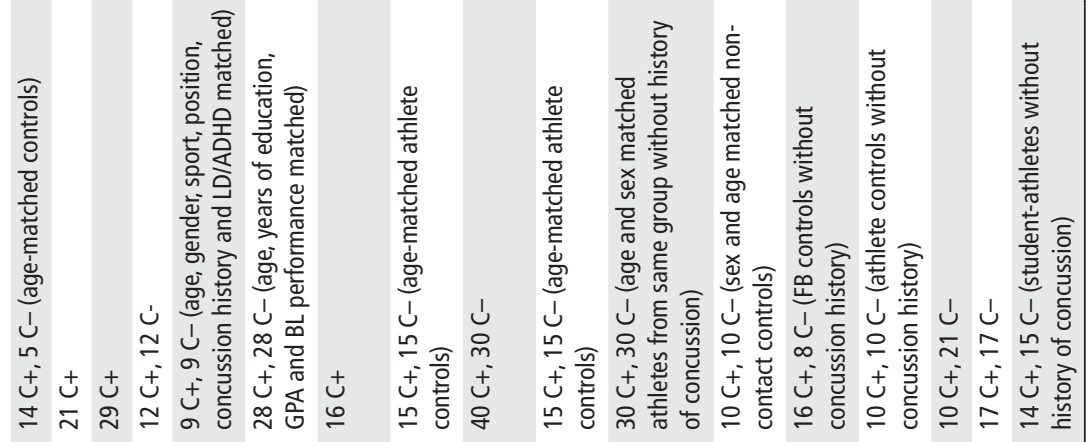

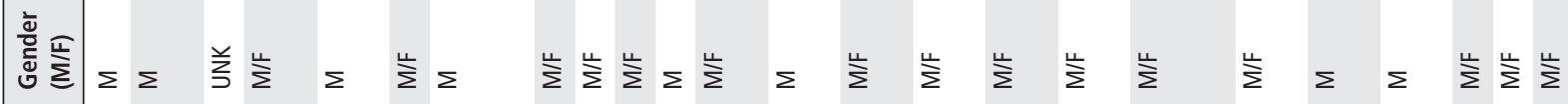

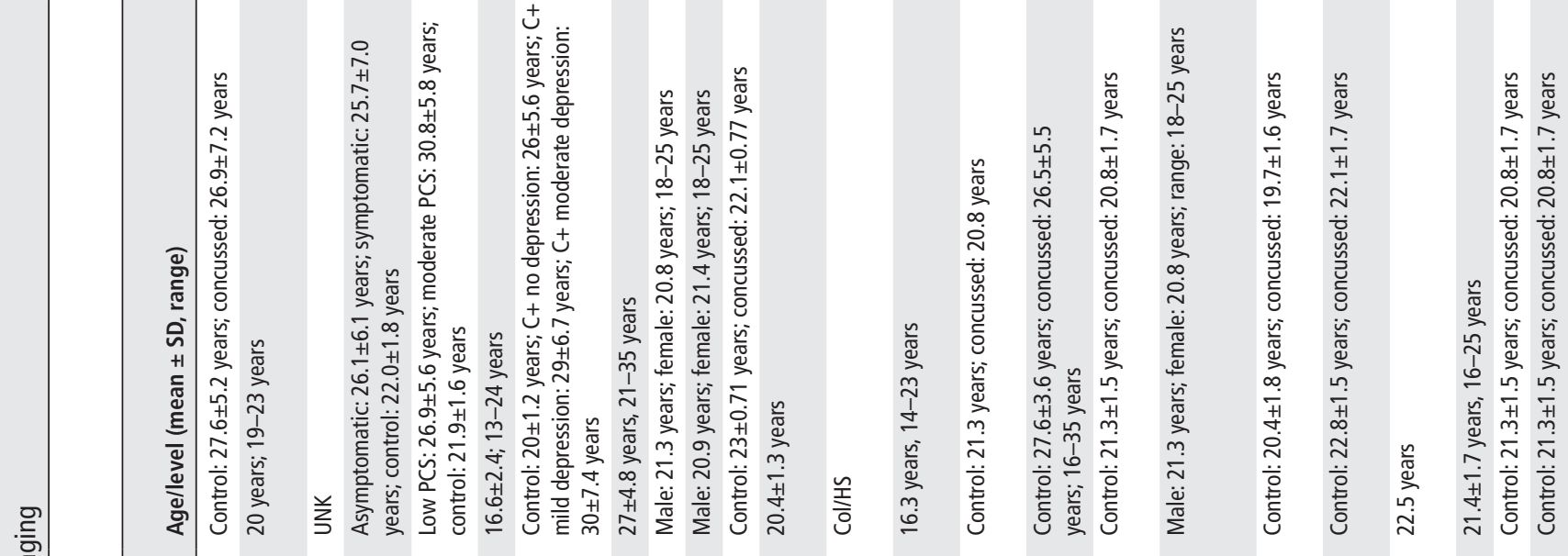

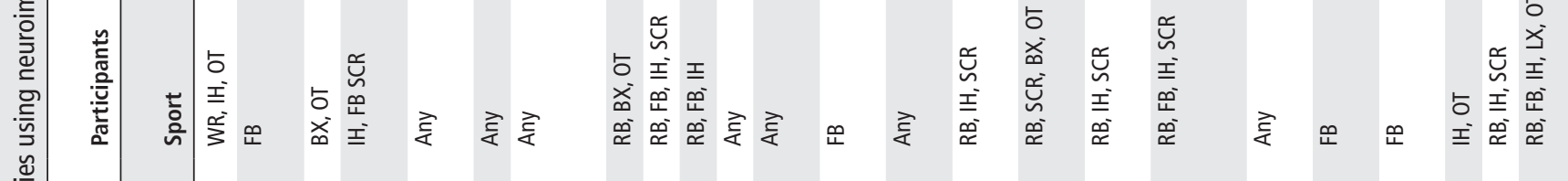

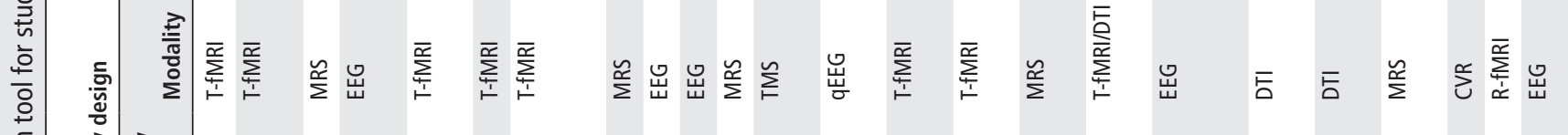
늘

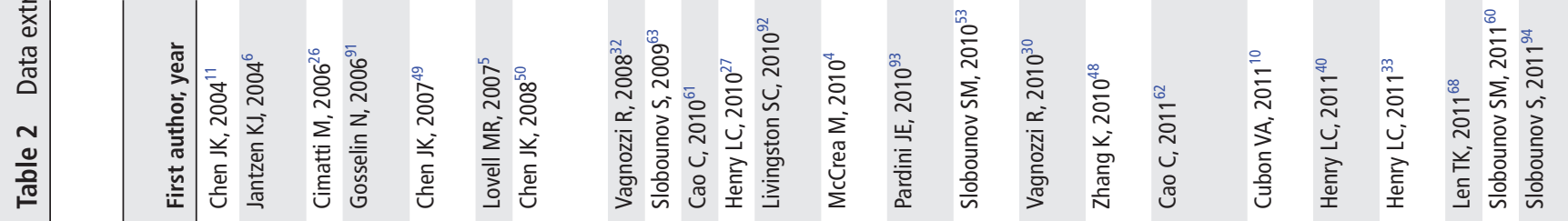




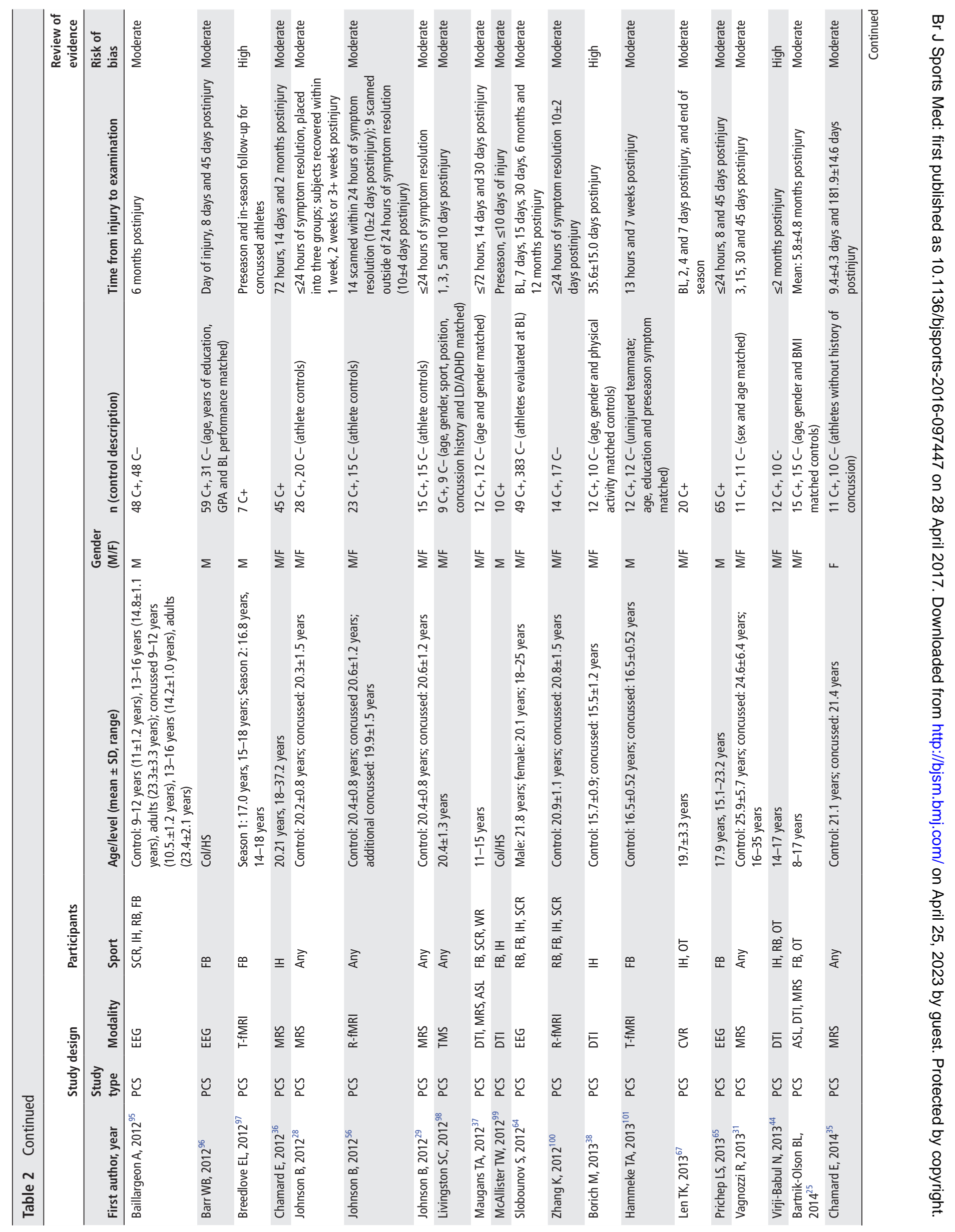




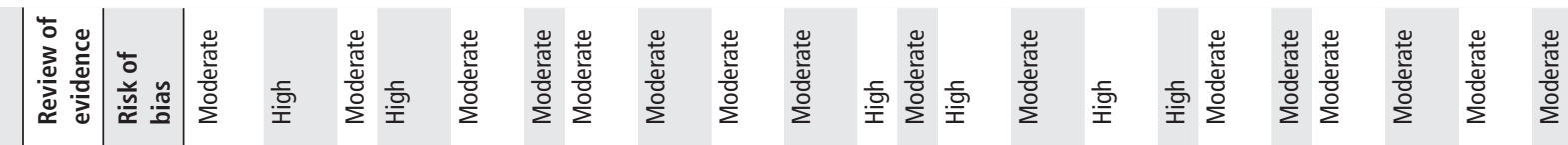

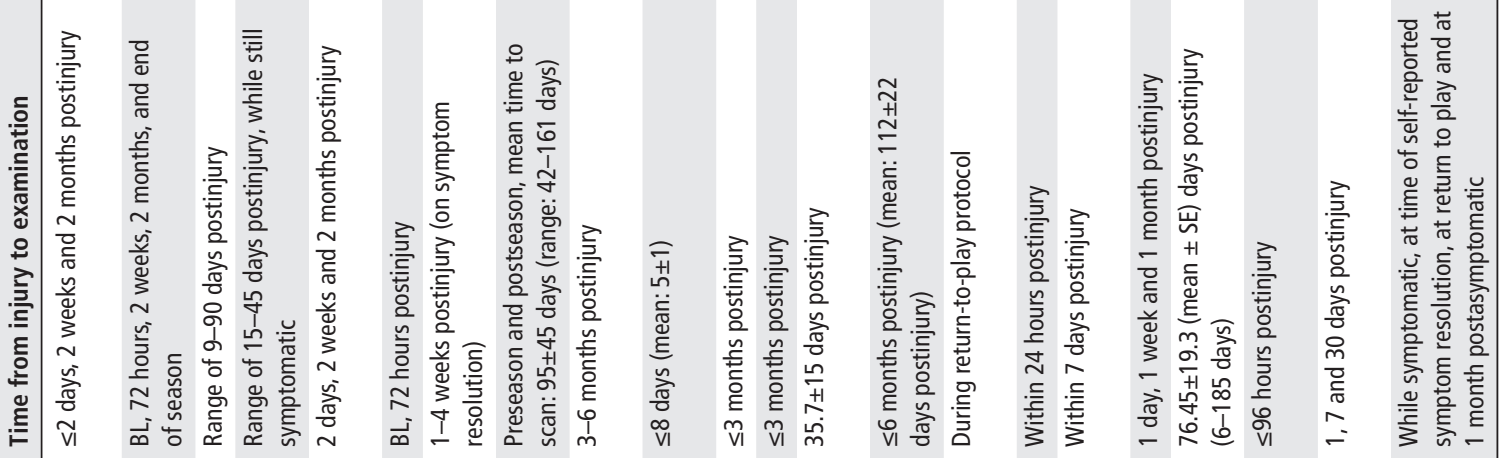

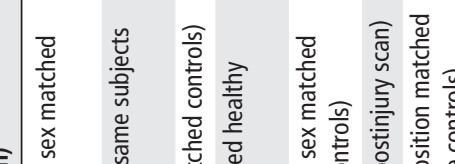

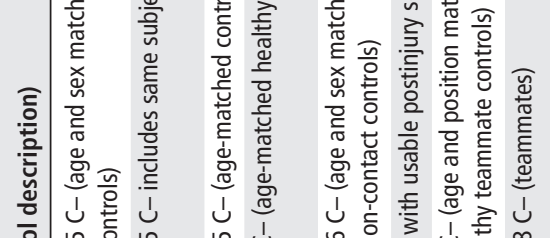

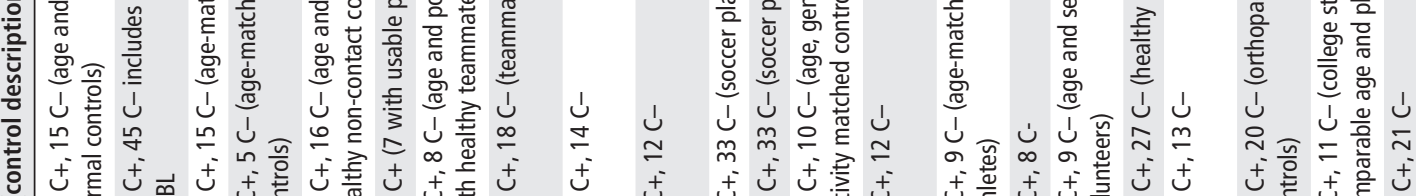

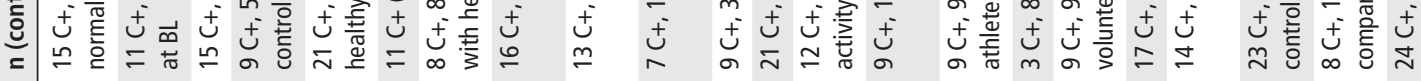

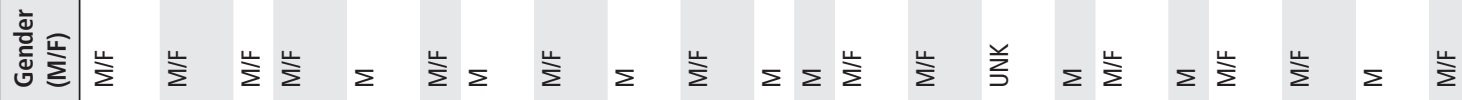

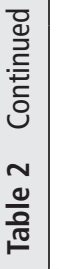

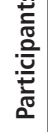

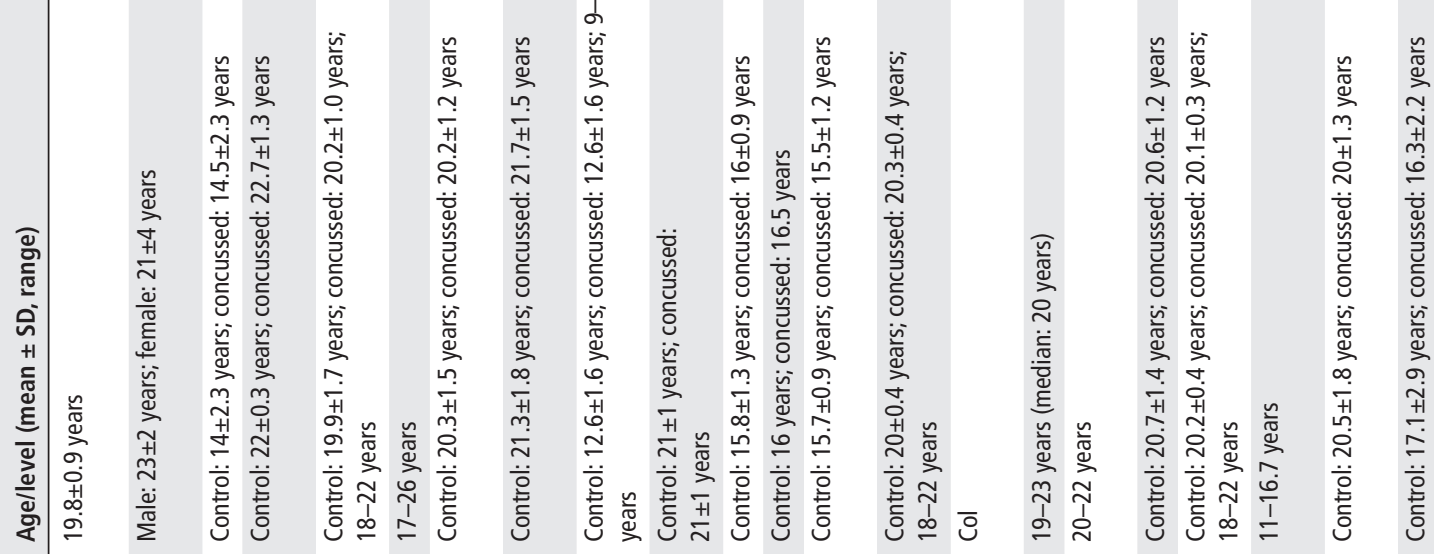

此

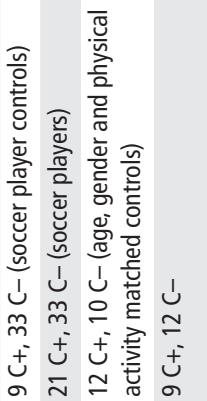

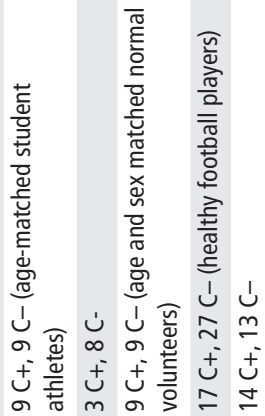

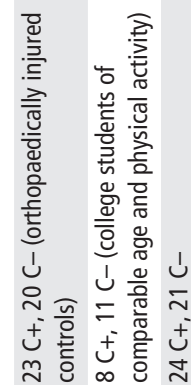

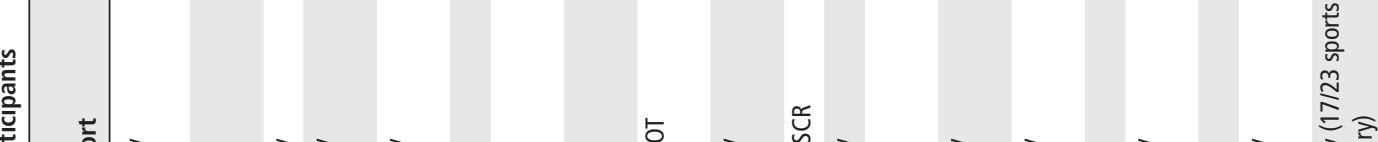

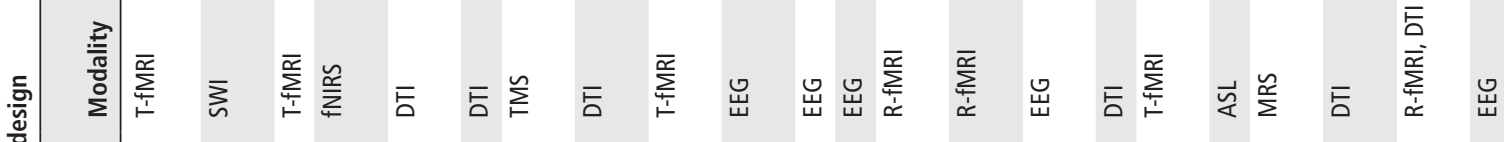
言站员

离

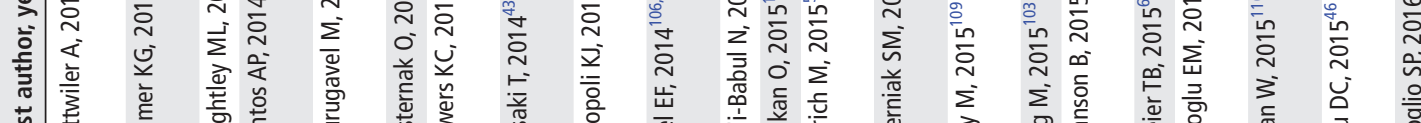

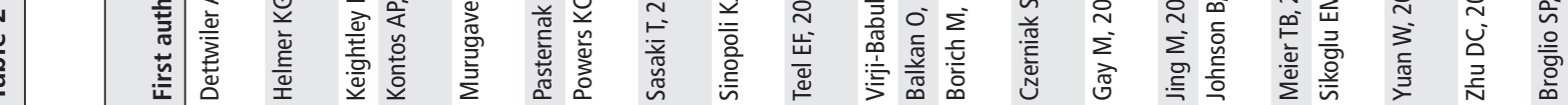




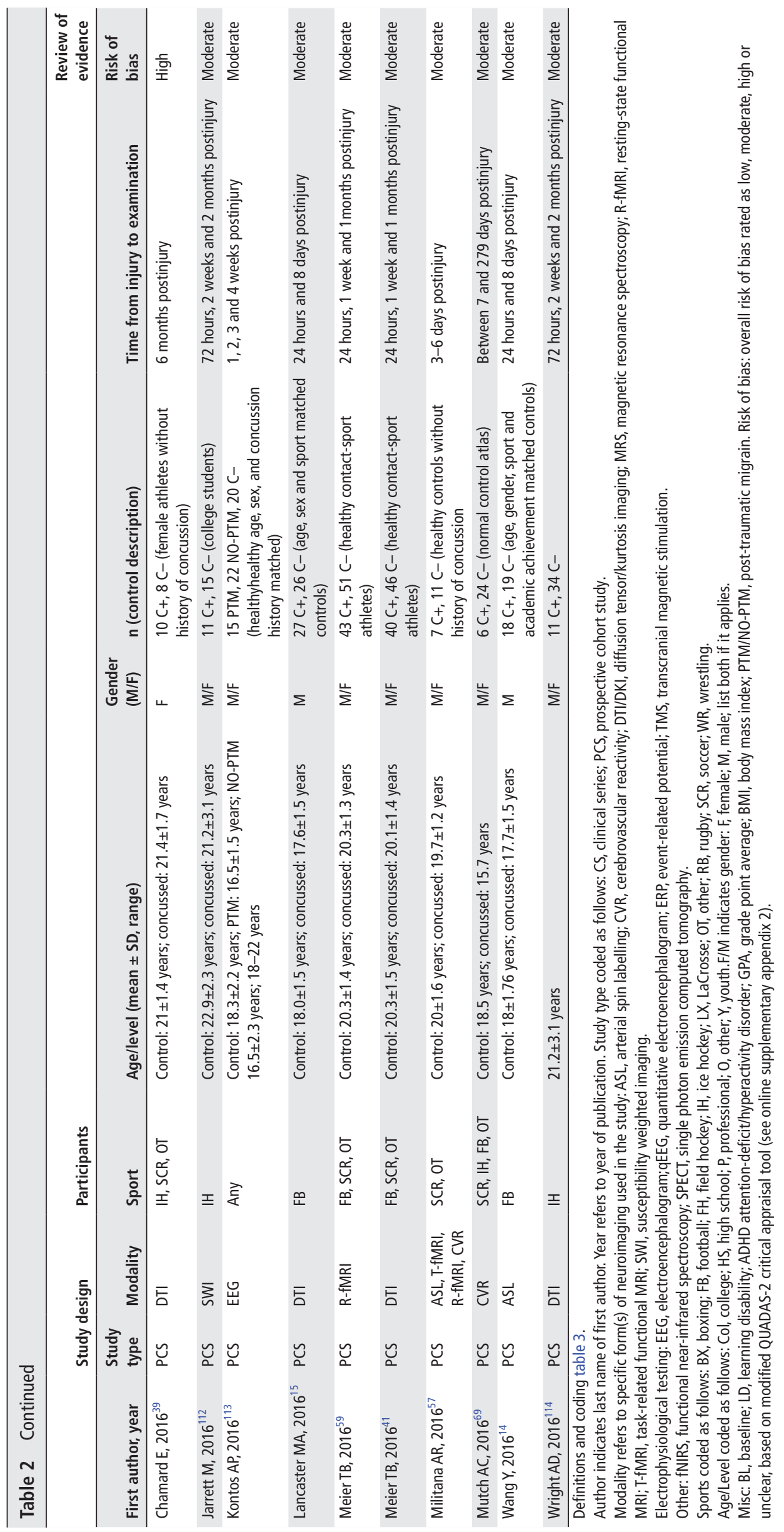




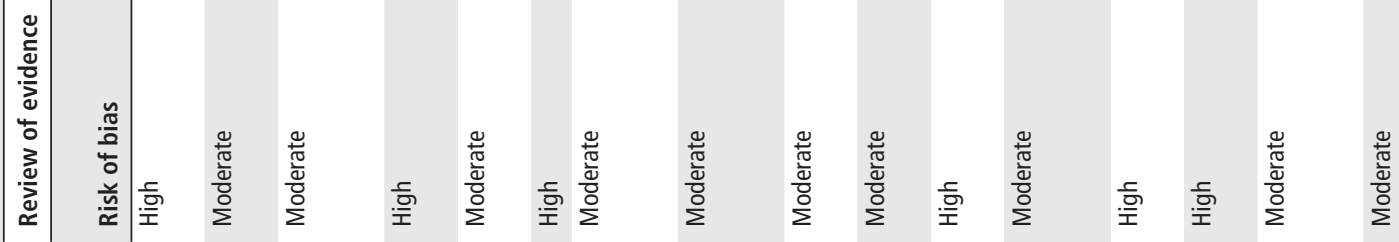

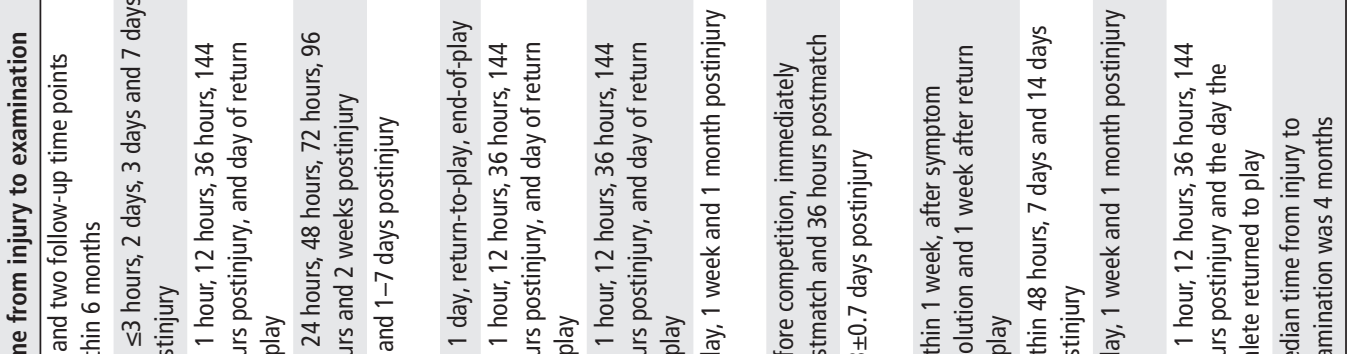

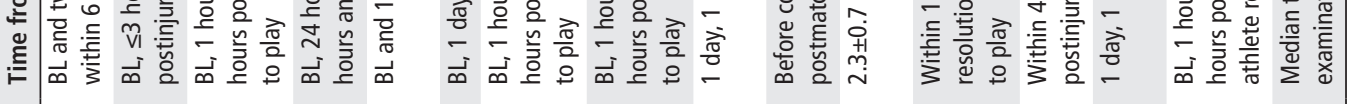

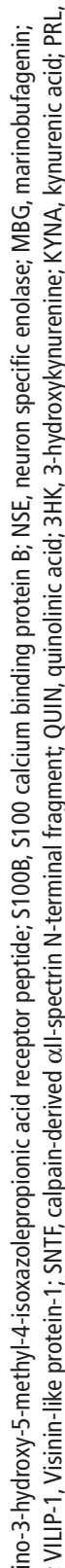

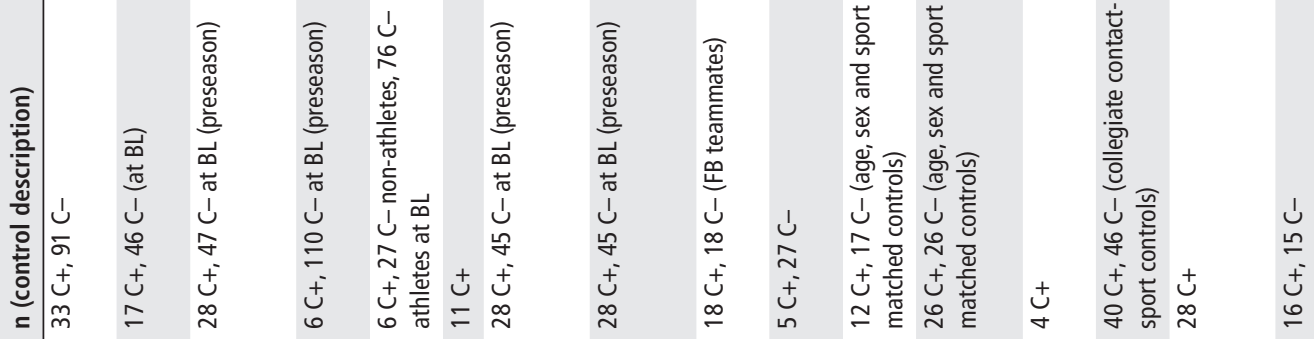

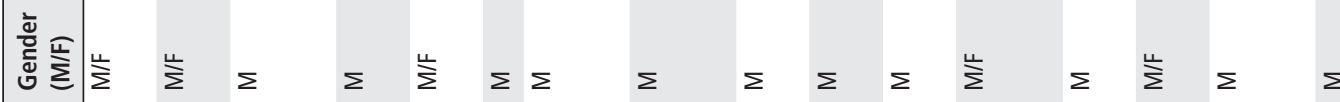

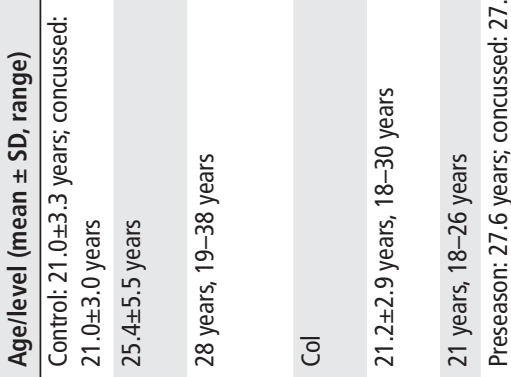

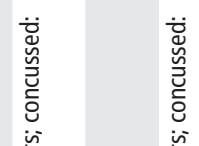

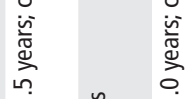

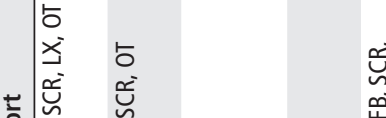

突

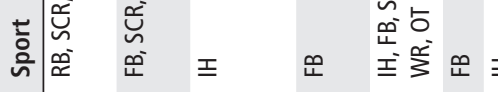

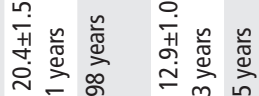

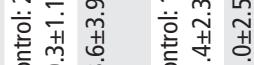
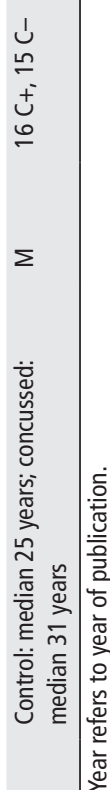

要艺

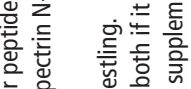

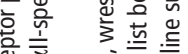

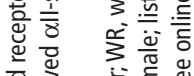

饶 离

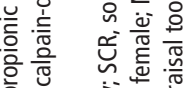

旁崖旁岕产

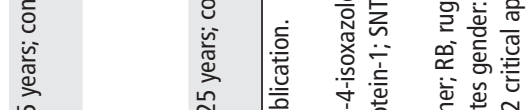

N

을.

ํำ

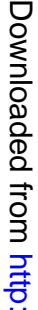

흠.

ᄋิ

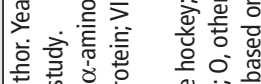
站客

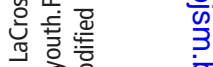


Table 4 Data extraction tool for studies using genetic testing

\begin{tabular}{|c|c|c|c|c|c|c|c|c|}
\hline \multirow[b]{2}{*}{ First author, year } & \multicolumn{2}{|c|}{ Study design } & \multicolumn{5}{|c|}{ Participants } & \multirow{2}{*}{$\begin{array}{l}\begin{array}{l}\text { Review of } \\
\text { evidence }\end{array} \\
\text { Risk of bias }\end{array}$} \\
\hline & $\begin{array}{l}\text { Study } \\
\text { type }\end{array}$ & Modality & Sport & $\begin{array}{l}\text { Age/level } \\
\text { (mean } \pm S D \text {, range) }\end{array}$ & $\begin{array}{l}\text { Gender } \\
\text { (M/F) }\end{array}$ & n (control description) & $\begin{array}{l}\text { Time from injury to } \\
\text { examination }\end{array}$ & \\
\hline McDevitt J, $2015^{87}$ & PCS & VNTR/GRIN2A & Any & $19.5 \pm 6.0$ years & $M / F$ & $87 \mathrm{C}+$ & $\begin{array}{l}\text { Recovery followed } \\
\text { prospectively; } \leq 60 \text { days } \\
\text { postinjury }\end{array}$ & High \\
\hline Gill J, $2016^{85}$ & PCS & RNA & Any & $\begin{array}{l}\text { Control: } 18.5 \pm 0.4 \text { years; } \\
\text { concussed: } 19.4 \pm 1.5 \text { years }\end{array}$ & $M / F$ & $15 C_{+}, 16 C_{-}$ & $\begin{array}{l}\text { BL, within } 6 \text { hours and } 7 \\
\text { days postinjury }\end{array}$ & Moderate \\
\hline Madura SA, $2016^{90}$ & PCS & SLC17A7 & Any & $20.0 \pm 6.3$ years & $M / F$ & $40 \mathrm{C}+$ & $\begin{array}{l}\text { Recovery followed } \\
\text { prospectively; } \leq 20 \text { days } \\
\text { postinjury }\end{array}$ & High \\
\hline $\begin{array}{l}\text { Merchant-Borna K, } \\
2016^{86}\end{array}$ & PCS & mRNA & $\begin{array}{l}\text { FB, IH, } \\
\text { SCR, LX }\end{array}$ & $\begin{array}{l}\text { Control: } 18.5 \pm 0.4 \text { years; } \\
\text { concussed: } 19.4 \pm 1.5 \text { years }\end{array}$ & $\mathrm{M} / \mathrm{F}$ & $\begin{array}{l}16 \mathrm{C}+, 16 \mathrm{C}-\text { teammate } \\
\text { controls ( } 253 \mathrm{C}-\text { at } \mathrm{BL} \\
\text { including } \mathrm{C}+\text { athletes) }\end{array}$ & $\begin{array}{l}\text { BL, within } 6 \text { hours, and } 7 \\
\text { days postinjury }\end{array}$ & Moderate \\
\hline Merritt VC, $2016^{89}$ & PCS & APOE & Any & $19.3 \pm 1.5$ years & $\mathrm{M} / \mathrm{F}$ & $45 C_{+}, 43 C_{-}$ & $10.0 \pm 14.3$ days postinjury & Moderate \\
\hline Merritt VC, $2016^{88}$ & CS & APOE & Any & $\begin{array}{l}\text { Positive } \epsilon 4 \text { allele group } \\
19.9 \pm 1.4 \text { years; negative } \epsilon 4 \\
\text { allele group } 20 \pm 1.6 \text { years }\end{array}$ & $\mathrm{M} / \mathrm{F}$ & $42 \mathrm{C}+$ & $\begin{array}{l}9.8 \pm 14.6 \text { days postinjury } \\
\text { (range of } 0-72 \text { days) }\end{array}$ & Moderate \\
\hline
\end{tabular}

Definitions and coding for Table 4: Author indicates last name of first author. Year refers to year of publication.

Study type coded as follows: CS, clinical series; PCS, prospective cohort study.

Modality refers to specific genetic marker(s) studied:VNTR, variable number tandem repeats; GRIN2A, N-methyl-D-aspartate receptor 2A; APOE, Apolipoprotein e; SLC17A7,

Solute Carrier Family 17 Member 7.

Sports coded as follows: $B X$, boxing; FB, football; FH, field hockey; IH, ice hockey; LX, LaCrosse; OT, other; RB, rugby; SCR, soccer; WR, wrestling.

Age/Level coded as follows: Col, college; HS, high school; O, other; P, professional; $Y$, youth.

F/M indicates gender: $F$, female; $M$, male; list both if it applies.

Misc: BL, baseline.

Risk of bias: overall risk of bias rated as low, moderate, high or unclear, based on modified QUADAS-2 critical appraisal tool

(see online supplementary appendix 2).

A rating for the overall level of evidence was assigned for each search area (neuroimaging, biomarkers and genetics) based on a simple hierarchical 'level of evidence' grading system, modified from that established by the Grading of Recommendations Assessment, Development, and Evaluation (GRADE) Working Group (see table 5). ${ }^{24}$ In cases of uncertainty, the full article was obtained and any disagreement resolved through discussion and consultation with a third reviewer. Finally, a qualitative synthesis of the overall level of evidence from each of the three searches was conducted by the subject matter experts and reported in each results section.

\begin{tabular}{ll}
\hline Table 5 & Quality of evidence grades \\
\hline Grade & Definition \\
\hline High & $\begin{array}{l}\text { High level of confidence in the strength of the existing findings } \\
\text { demonstrating reliability, validity and clinical utility of the tool(s) for use } \\
\text { in the assessment of SRC }\end{array}$ \\
Moderate & $\begin{array}{l}\text { Moderate level of confidence in the strength of the existing findings } \\
\text { demonstrating reliability, validity and clinical utility of the tool(s) for use } \\
\text { in the assessment of SRC }\end{array}$ \\
Low & $\begin{array}{l}\text { Low level of confidence in the strength of the existing findings } \\
\text { demonstrating reliability, validity and clinical utility of the tool(s) for use } \\
\text { in the assessment of SRC }\end{array}$ \\
Very low & $\begin{array}{l}\text { Very Low level of confidence in the strength of the existing findings } \\
\text { demonstrating reliability, validity and clinical utility of the tool(s) for use } \\
\text { in the assessment of SRC }\end{array}$
\end{tabular}

Quality of evidence is a continuum; any discrete categorisation involves some degree of arbitrariness. Nevertheless, advantages of simplicity, transparency and vividness outweigh these limitations.

SRC, sport-related concussion.

\section{RESULTS}

The electronic literature database search identified 3222 articles. After applying additional requirements and eliminating duplicate articles, a total of 98 qualified for further review (76 neuroimaging, 16 biomarkers and 6 genetic testing). Tables $2-4$ provide a summary of key findings from studies in each domain (neuroimaging, biomarkers and genetic testing).

\section{Neuroimaging studies}

Seventy-six studies using neuroimaging and electrophysiological measures revealed significant effects of SRC by each of the modalities assessed in this review. These included diffusion tensor imaging (DTI) $(\mathrm{n}=18)$, task-based functional MRI (fMRI) $(n=15)$, electroencephalogram $(\mathrm{EEG}) /$ quantitative-EEG (qEEG:n=16), magnetic resonance spectroscopy (MRS) $(n=13)$, and resting-state fMRI $(n=8)$, as well as fewer studies that used measures of cerebrovascular reactivity $(\mathrm{CVR})(\mathrm{n}=4)$, arterial spin labelling $(n=5)$, transcranial magnetic stimulation (TMS) $(\mathrm{n}=3)$, susceptibility weighted imaging $(\mathrm{n}=2)$ and functional near-infrared spectroscopy $(n=1)$. Although EEG and TMS were not explicitly referenced in our assigned review questions, the decision was made to include them in the neuroimaging section of the review based on published reports using these technologies in the study of SRC. The limited number of studies for any specific marker, the varying time frames, the lack of standardisation and the different analyses employed make the determination of consistent patterns difficult.

Nevertheless, some consistent patterns do emerge. With MRS there is a reduction of $\mathrm{N}$-acetylaspartate (NAA; relative to creatine and/or choline) predominately in white matter, ${ }^{25-32}$ with some evidence of acute reduction with subsequent recovery by 
30 days postinjury. ${ }^{3032}$ Others, however, have reported decreased NAA levels more chronically. ${ }^{25} 33$ Fewer studies have observed the effects of SRC on other metabolites, ${ }^{27} 3133-35$ although null results have also been reported. ${ }^{3637}$

The majority of DTI work reports a decrease in mean diffusivity and/or an increase in fractional anisotropy in white matter within 6 months postinjury, ${ }^{15}{ }^{38-44}$ although opposite patterns or null results have been reported..$^{103745}$ In addition, most observed a reduction in radial diffusivity, ${ }^{38} 394243$ whereas both increases and decreases in axial diffusivity have been described. ${ }^{39}$ 404243

The results from task-fMRI studies are more variable. The majority used a working memory paradigm leading to varying and seemingly contradictory findings, with reports of increased $^{47} 48$ and decreased activity in task-related networks (eg, dorsolateral prefrontal cortex). ${ }^{11}{ }^{49-51}$ Multiple studies, however, have reported additional activity outside of the core task regions following SRC in a variety of tasks. ${ }^{11495052-54}$ Time since injury, task variables and symptom presentation are likely modifying factors. In addition, although most studies investigated working memory, the type and number of stimuli used (ie, low vs high working memory 'load') varied largely, which may explain apparent discordance in hypoactivation versus hyperactivation results reported.

Findings from the resting-state fMRI literature also vary, likely because methodologies differ. Nevertheless, the default mode network $(\mathrm{DMN})$ is the most extensively studied network in the SRC literature. Results have varied across studies, however, as both increases and decreases in connectivity between DMN regions have been reported across and within studies. ${ }^{46} 55-57$ Altered functional connectivity has also been observed relative to executive function, visual and motor networks. ${ }^{558-60}$

Several studies have demonstrated the effects of SRC on EEG/ qEEG at rest or during different task conditions. Importantly, multiple studies assessed electrophysiological changes following injury relative to a preinjury baseline measure. ${ }^{461-64}$ For example, $\mathrm{Cao}$ and Slobounov have reported differences in several EEG metrics postinjury relative to baseline. ${ }^{61}{ }^{62}$ Measures from qEEG have also been shown to be altered at 8 days post-SRC relative to baseline, ${ }^{4}$ and have been associated with concussion severity, underlining the potential of electrophysiological measurements in the assessment of SRC. ${ }^{65}$

Consistent findings across the other modalities are difficult to assess due to the limited number of studies. However, four of five studies that investigated cerebral blood flow following SRC reported reductions at the acute and subacute phases (days to weeks), ${ }^{143766}$ and even at more chronic time points ( $\sim 5$ months). ${ }^{25}$ An additional study reported no differences in resting cerebral blood flow, ${ }^{57}$ although it did report an increase in CVR, consistent with others that showed impaired CVR. ${ }^{67-69}$

The majority of neuroimaging studies, although of high quality and informative, had at least a moderate risk of bias based on the scoring criteria outlined in the modified QUADAS- 2 tool. Most common was the lack of generalisability due to the inclusion of limited age ranges, male athletes focus and/or limited sample sizes. Additional factors included a lack of appropriate control groups, lack of preinjury enrolment and potential for measurement bias due to limited information regarding the definition/diagnosis of mTBI/SRC. Also, publication bias that limits reporting null results should be acknowledged, although this issue is not unique to the current literature.

Given the above, it is our opinion that the level of evidence for the role of these neuroimaging and electrophysiological measures in the clinical assessment of SRC is low (see table 5) because the most studies reviewed were not designed to specifically assess clinical potential. Rather, they aimed to assess the effects of SRC using that marker. Therefore, for the purposes of this review, we make a distinction between the level of evidence for the utilisation of these markers for clinical assessment of SRC and their use to characterise the pathophysiology involved. It is our opinion that there is a significant role for neuroimaging and electrophysiological measures in characterising the pathophysiology of SRC.

\section{Fluid biomarker studies}

Sixteen papers met our inclusion/exclusion criteria relevant to diagnosis or prognosis following sport concussion using fluid biomarkers (see table 3). Fourteen papers analysed blood (plasma or serum) biomarkers, one paper analysed salivary cortisol, and one paper analysed CSF. Eleven papers found significant alterations in one or more of the following blood biomarkers that could potentially aid in the diagnosis of SRC: $\alpha$-amino-3-hydroxy-5-methyl-4-isoxazolepropionic acid receptor peptide (AMPAR), ${ }^{70}$ S100 calcium binding protein B (s100B), ${ }^{71-74}$ total tau, ${ }^{72}$ marinobufagenin, ${ }^{75}$ plasma soluble cellular prion protein, ${ }^{76}$ glial fibrillary acidic protein, ${ }^{76}$ neuron-specific enolase (NSE), ${ }^{77}$ calpain-derived $\alpha$ II-spectrin $\mathrm{N}$-terminal fragment (SNTF), ${ }^{78}$ tau- $\mathrm{C}^{79}$ and metabolomics profiling. ${ }^{80}$ In contrast, NSE, ${ }^{72}$ visinin-like protein- $1,{ }^{74}$ total tau, ${ }^{417481}$ tau- $\mathrm{A}^{79}$ and salivary cortisol ${ }^{82}$ did not distinguish concussed athletes from non-concussed athletes. Several serum biomarkers such as SNTF, ${ }^{78}$ quinolinic acid, ${ }^{83}$ prolactin $^{84}$ and tau- $\mathrm{A}^{79}$ showed early evidence in predicting outcomes following sport concussion. Finally, decreased levels of amyloid-beta-42 and increased neurofilament light in CSF were observed in athletes with postconcussion syndrome, although these results were largely driven by athletes with postconcussion syndrome duration of more than 1 year. $^{81}$

Overall risk of bias rating for the fluid biomarker papers ranged from moderate to high. High risk of bias occurred most commonly due to limited external validity and poor generalisability in terms of gender (males only), age (collegiate athletes) and sport (most often football or ice hockey). Other factors contributing to moderate to high risk included small sample sizes, no control subjects and lack of preseason assessment. Based on our review of the existing literature, the overall level of evidence for use of fluid biomarkers in the clinical assessment of SRC is considered low (see table 5). Early but limited evidence does indicate, however, that fluid biomarkers may inform our scientific understanding of the underlying pathophysiology of concussion in humans.

\section{Genetic testing studies}

Outcome after SRC is variable and unpredictable, suggesting that factors other than injury severity, such as host genotype, are important modulators. Emerging literature on genetic predictors of TBI highlights their relevance, ${ }^{13}$ and suggests four broad contexts in which genetic variation could modulate outcome: (1) modulation of the impact of a given neurotrauma 'dose' in terms of injury extent, (2) modulation of repair mechanisms, thus impacting trajectory of recovery and ultimate functional outcome, (3) modulation of preinjury traits (eg, resilience) or cognition (cognitive reserve), and (4) interactions between genetic vulnerabilities to neurobehavioural disorders and neurotrauma (ie, role of comorbidities). 
Our search strategy identified six papers specifically addressing genetic factors in SRC. Of these, two (from the same group) studied gene expression acutely (within 6 hours) and subacutely (within 7 days) after concussion in essentially the same cohort of collegiate athletes. ${ }^{85} 86$ Comparison of preseason baseline and postinjury samples in this cohort of college athletes showed differential expression of genes driving immune and inflammatory pathways acutely, and hypothalamic-adrenal-pituitary axis function subacutely.

The other four papers tested hypotheses related to specific candidate genes. McDevitt et al (2015) ${ }^{87}$ studied the role of variable number tandem repeat (VNTR) alleles in the promoter region of GRIN2A (a gene coding an NMDA glutamate receptor subunit) in a cohort of 87 concussed athletes. Recovery times over 60 days were associated with the long variant of the allele. Two studies from Merritt and colleagues ${ }^{88} 89$ found an association of the APOEe4 allele with total symptom score, cognitive and physical symptoms, and the presence and severity of headache in a cohort of concussed collegiate athletes assessed a mean of 10 days after injury. Another study in a cohort of 40 concussed collegiate athletes examined the rs74174284 polymorphism in the promoter region of the SLC17A7 gene, and found that the C allele was associated with prolonged recovery times and poorer motor performance. ${ }^{90}$

Overall, the risk of bias in reviewed studies was moderate to high (related to small sample size, inadequate representation across age/gender/sport, poorly defined diagnostic methods for concussion, referral bias and failure to include non-concussed teammates exposed to repetitive head impacts as controls). The overall level of evidence for clinical application was determined as low (see table 5), prohibiting endorsement of genetic testing for clinical evaluation or management of SRC. However, the available studies provide 'proof of concept' that genetic assessment might identify those at risk for poor outcomes from SRC, even before injury. Although genetic assessment cannot yet be endorsed as a clinical tool in SRC management, it certainly warrants future research.

\section{DISCUSSION}

Over the past 20 years, there has been significant progress in our understanding of the underlying neurobiology and pathophysiology of mTBI and concussion from both basic animal models and human studies. Collectively, the fact that nearly 100 studies included in our systematic review have employed advanced technologies specifically in the study of SRC over the past 15 years is a clear indication of how research in this arena has progressed. That said, the current state of this work is limited by several factors, including the relatively small number of studies investigating each modality, small sample sizes across studies, varied study design, outcome measures and analytic methods, and lack of consistency in the timing of postinjury data collection points, and risk of bias due to very limited generalisability across studies.

The collective body included in our systematic review was considered to have at least moderate risk of bias based on our assessment. The risk of bias rating was clearly affected more by limited generalisability than by any inherent or created bias in the traditional sense associated with investigator conflicts, research design, outside influence, etc. Generalisability was limited largely by the size and scope of the study sample (eg, restricted to single gender or sport) in several studies. This will be an important consideration for future research efforts to overcome.

Ultimately, determining the utility of these advanced technologies likely divides into two parallel discussions: (1) their use as research tools to study changes in brain structure and function associated with SRC, and (2) their clinical application as diagnostic and prognostic markers of injury and recovery to assist in the assessment and management of athletes with SRC, over and above our current clinical tools. In terms of their current readiness for clinical application, our systematic review rated the level of evidence as low for advanced neuroimaging, low for fluid biomarkers and low for genetic testing (see table 5). At the same time, however, our systematic review generally supports the utility of advanced neuroimaging, fluid and genetic biomarkers in studies aimed at identifying the neurobiological effects of concussion and the natural history of neurobiological recovery after injury.

Our rating of the neuroimaging evidence is consistent with a recently published position statement from the Radiologic Society for North America on the use of advanced neuroimaging modalities in the assessment of TBI. Advanced neuroimaging is sure to play a critical role in the future study of SRC. Similarly, the use of fluid biomarkers has advanced our understanding of the pathophysiology of SRC, but the validation of these markers is in the preliminary stages. Clinically, blood biomarkers require hours of analysis and access to a basic science laboratory, which is not currently practical for assessing acute SRC in the competitive sports setting. Future studies with larger samples sizes, standardised protocols, and more stringent study designs that include baseline testing, appropriate controls, blinded analysis and real-life outcome measures, are needed before these markers are translated from 'bench to bedside'.

Further research is critical to determine whether the time course of neurobiological recovery is 'coupled' with clinical or subjective recovery (eg, resolutions of signs, symptoms and functional impairments), or the extent to which the tail of neurobiological recovery extends beyond the observed endpoint of clinical recovery. In a research setting, this work is a critical next step towards understanding the pathophysiology of concussion in humans. From a clinical perspective, discoveries along these lines also have translational significance to determining when athletes achieve full recovery and are fit to safely return to activity without elevated risk or vulnerability to additional injury. Further, the novel technologies may enable researchers to better determine the effects of repetitive head impact exposure on brain structure and function, even in the absence of frank concussion.

It should be acknowledged that genetic testing is not intended for use in the diagnosis of concussion, but has importance in determining the factors that influence risk of injury and recovery after SRC. Data from genetic studies may provide intriguing insights about the host response to concussion, although the absence of data on how such differential gene expression affects outcome limits inferences about whether these changes constitute a contributory disease mechanism or a reparative host response. There is a clear need for large-scale research efforts to determine the role that genetics plays in the broader space of TBI and with specific relevance to athletes with SRC.

Given the complex pathophysiology of concussion, it is considered unlikely that a singular diagnostic and prognostic biomarker solution will prevail. Rather, an integrated combination of specific imaging, fluid and genetic biomarkers is predicted to have the greatest utility to clinical care. Ultimately, research on neurobiological and genetic aspects of $\mathrm{SRC}$ is predicted to have major translational significance to evidence-based approaches to clinical management of athletes with SRC, much like applied clinical research has had over the past 20 years. 


\section{RECOMMENDATIONS FOR FUTURE RESEARCH DIRECTIONS}

We offer the following recommendations in order to further accelerate the field's understanding of the pathophysiology of SRC and to determine the potential of these advanced technologies for the clinical assessment of SRC:

1. Enrolment of larger sample sizes with greater representation across sport, age and sex, particularly studies involving youth and female athletes.

2. Preinjury enrolment of athletes to allow truly prospective recruitment of consecutive injuries. Although often impractical for neuroimaging, collecting biomarkers at preinjury would represent an ideal study design.

3. Studies driven by a priori hypotheses based on current evidence on neuropathophysiology of concussion from preclinical models and non-sport head injury. Exploratory (hypothesis-generating) research may also lead to important breakthroughs.

4. Careful consideration regarding the control groups used (eg, controlling for head impact exposure vs concussive injury) in order to advance our understanding of the effects of both concussion and repetitive head impact exposure (without concussion) on brain structure and function.

5. Adopt standard injury criteria, time frames of assessment and multidimensional measures of outcome and recovery, as well as metrics and processing strategies within modalities/ metrics to allow comparison across studies (eg, National Institute of Neurological Disorders and Stroke TBI Common Data Elements, Canadian Pediatric mTBI Common Data Elements).

6. Simultaneous assessment of multiple biomarkers to determine the additive value of each marker in the clinical assessment of SRC.

7. Rather than simply showing associations between measurements and diagnosis or outcome, it is important to demonstrate additional benefit of novel biomarkers over current approaches.

8. Clinical utility is more likely to derive from biomarker combinations rather than individual biomarkers; we recommend the exploration of biomarker panels, both within and across techniques.

Several limitations of our systematic search and review warrant consideration. First, we recognise that the scope of our assigned systematic review was purposefully broad in order to inform the 5th International Consensus Conference on Concussion in Sport, but still rendered a relatively small number of qualifying studies, particularly with respect to fluid biomarkers and genetics. In addition to the aforementioned methodological limitations that impact the quality of evidence from reviewed studies, we also acknowledge the potential for publication bias (eg, public reporting of positive findings only) affecting our results of the systematic review. Further, articles included for review were limited to those published in English language, raising the prospect that studies published in other languages are not represented here.

\section{CONCLUSION}

Our results indicate that advanced neuroimaging, fluid biomarkers and genetic testing show significant promise as research tools in the study of SRC, but require considerable further research to determine their ultimate utility in a clinical setting. Future research efforts should address current gaps to help guide and accelerate clinical translation.
What are the findings?

- Over the past two decades, there has been a major expansion of research on the neurobiology of SRC, marked by the increase in number of studies that have employed advanced neuroimaging and fluid biomarkers to measure the acute effects of SRC on brain structure and function.

- These technologies show significant promise as research tools, but require considerable further research to determine their ultimate clinical utility.

- Future research efforts should address current gaps that limit clinical translation, including greater consistency across the most advanced technology platforms, larger and more representative study samples (across age, gender, sport, etc), and more rigorous analytic methods across studies.

How might it impact on clinical practice in the future?

- Ultimately, this line of research on neurobiological and genetic aspects of SRC is predicted to have major translational significance to evidence-based approaches to clinical management of athletes with SRC, much like applied clinical research has had over the past 20 years.

\section{Author affiliations}

${ }^{1}$ Department of Neurosurgery, Medical College of Wisconsin, Milwaukee, Wisconsin, USA

${ }^{2}$ Department of Cell Biology, Neurobiology and Anatomy, Medical College of

Wisconsin, Milwaukee, Wisconsin, USA

${ }^{3}$ Departments of Neurology and Neurosurgery, McGill University, Montreal, Quebec, Canada

${ }^{4}$ Research Institute and Department of Psychology, McGill University Health Centre, Montreal, Quebec, Canada

${ }^{5}$ Department of Psychology and Neuroscience Center, Brigham Young University,

Provo, Utah, USA

${ }^{6}$ Clinical Neurosciences, University of Calgary, Calgary, Alberta, Canada

${ }^{7}$ Department of Neurosurgery, University of California San Francisco, San Francisco,

California, USA

${ }^{8}$ Division of Anaesthesia, University of Cambridge, Cambridge, UK

${ }^{9}$ Cognitive Neuroscience Unit, Montreal Neurological Institute and Hospital,

Montreal, Quebec, Canada

${ }^{10}$ Department of Psychiatry, Indiana University School of Medicine, Indianapolis, Indiana, USA

${ }^{11}$ Faculty of Kinesiology, University of Calgary, Calgary, Alberta, Canada

Acknowledgements The authors acknowledge and appreciate the assistance of Elizabeth Suelzer, MLIS, medical librarian at the Medical College of Wisconsin, with the protocol and literature search for this systematic review.

Contributors All authors contributed to article review and interpretation of data, drafting and revision of the manuscript, and final approval of the manuscript, and agreed to be accountable for all aspects of the work.

Competing interests None declared.

Provenance and peer review Not commissioned; externally peer reviewed.

(c) Article author(s) (or their employer(s) unless otherwise stated in the text of the article) 2017. All rights reserved. No commercial use is permitted unless otherwise expressly granted.

\section{REFERENCES}

1 McCrea M, Iverson GL, McAllister TW, et al. An integrated review of recovery after mild traumatic brain injury (MTBI): implications for clinical management. Clin Neuropsychol 2009;23:1368-90.

2 Belanger HG, Vanderploeg RD. The neuropsychological impact of sports-related concussion: a meta-analysis. J Int Neuropsychol Soc 2005;11:345-57.

3 McCrea M, Guskiewicz KM, Marshall SW, et al. Acute effects and recovery time following concussion in collegiate football players: the NCAA concussion study. Jama 2003;290:2556-63. 
4 McCrea M, Prichep L, Powell MR, et al. Acute effects and recovery after sport-related concussion: a neurocognitive and quantitative brain electrical activity study. J Head Trauma Rehabil 2010;25:283-92.

5 Lovell MR, Pardini JE, Welling J, et al. Functional brain abnormalities are related to clinical recovery and time to return-to-play in Athletes. Neurosurgery 2007:61:352-60. discussion 359-360.

6 Jantzen KJ, Anderson B, Steinberg FL, et al. A prospective functional MR imaging study of mild traumatic brain injury in college football players. AJNR Am J Neuroradiol 2004;25:738-45.

7 Wilde EA, McCauley SR, Hunter JV, et al. Diffusion tensor imaging of acute mild traumatic brain injury in adolescents. Neurology 2008;70:948-55.

8 Chu Z, Wilde EA, Hunter JV, et al. Voxel-based analysis of diffusion tensor imaging in mild traumatic brain injury in adolescents. Am J Neuroradio/ 2010;31:340-6.

9 Mayer AR, Ling J, Mannell MV, et al. A prospective diffusion tensor imaging study in mild traumatic brain injury. Neurology 2010;74:643-50.

10 Cubon VA, Putukian M, Boyer C, et al. A diffusion tensor imaging study on the white matter skeleton in individuals with sports-related concussion. J Neurotrauma 2011;28:189-201.

11 Chen JK, Johnston KM, Frey S, et al. Functional abnormalities in symptomatic concussed Athletes: an fMRI study. Neuroimage 2004;22:68-82.

12 Chen JK, Johnston KM, Petrides $M$, et al. Recovery from mild head injury in sports: evidence from serial functional magnetic resonance imaging studies in male Athletes. Clin J Sport Med 2008;18:241-7.

13 McAllister TW. Genetic factors in traumatic brain injury. Handb Clin Neurol 2015;128:723-39.

14 Wang Y, Nelson LD, LaRoche AA, et al. Cerebral blood flow alterations in acute sportrelated concussion. J Neurotrauma 2016;33:1227-36.

15 Lancaster MA, Olson DV, McCrea MA, et al. Acute white matter changes following sport-related concussion: a serial diffusion tensor and diffusion kurtosis tensor imaging study. Hum Brain Mapp 2016:37:3821-34.

16 Higgins J, Green S. The Cochrane Collaboration. Cochrane handbook for systamatic reviews of interventions-Version 5.1.0, 2011.

17 PROSPERO: international prospective register of systematic reviews. $2016 \mathrm{https}: / /$ www.crd.york.ac.uk/PROSPERO/.

18 Gardner A, Kay-Lambkin F, Stanwell P, et al. A systematic review of diffusion tensor imaging findings in sports-related concussion. J Neurotrauma 2012;29:2521-38.

19 Panenka WJ, Gardner AJ, Dretsch MN, et al. Systematic review of genetic risk factors for sustaining a mild traumatic brain injury. J Neurotrauma 2017.

20 Papa L, Ramia MM, Edwards D, et al. Systematic review of clinical studies examining biomarkers of brain injury in athletes after sports-related concussion. J Neurotrauma 2015:32:661-73

21 Gardner A, Iverson GL, Stanwell P. A systematic review of proton magnetic resonance spectroscopy findings in sport-related concussion. J Neurotrauma 2014;31:1-18.

22 Raji CA, Tarzwell R, Pavel D, et al. Clinical utility of SPECT neuroimaging in the diagnosis and treatment of traumatic brain injury: a systematic review. PLoS One 2014;9:e91088.

23 Schueler S, Schuetz GM, Dewey M. The revised QUADAS-2 tool. Ann Intern Med 2012;156:323. author reply 323-324.

24 Maxwell L, Santesso N, Tugwell PS, et al. Method guidelines for Cochrane musculoskeletal group systematic reviews. J Rheumatol 2006;33:2304-11.

25 Bartnik-Olson BL, Holshouser B, Wang $\mathrm{H}$, et al. Impaired neurovascular unit function contributes to persistent symptoms after concussion: a pilot study. J Neurotrauma 2014;31:1497-506

26 Cimatti M. Assessment of metabolic cerebral damage using proton magnetic resonance spectroscopy in mild traumatic brain injury. J Neurosurg Sci 2006;50:83-8

27 Henry LC, Tremblay S, Boulanger Y, et al. Neurometabolic changes in the acute phase after sports concussions correlate with symptom severity. J Neurotrauma 2010;27:65-76.

28 Johnson B, Gay M, Zhang K, et al. The use of magnetic resonance spectroscopy in the subacute evaluation of athletes recovering from single and multiple mild traumatic brain injury. J Neurotrauma 2012;29:2297-304.

29 Johnson B, Zhang K, Gay M, et al. Metabolic alterations in corpus callosum may compromise brain functional connectivity in MTBI patients: an 1H-MRS study. Neurosci Lett 2012:509:5-8.

30 Vagnozzi R, Signoretti S, Cristofori L, et al. Assessment of metabolic brain damage and recovery following mild traumatic brain injury: a multicentre, proton magnetic resonance spectroscopic study in concussed patients. Brain 2010;133:3232-42.

31 Vagnozzi R, Signoretti S, Floris $\mathrm{R}$, et al. Decrease in N-acetylaspartate following concussion may be coupled to decrease in creatine. J Head Trauma Rehabil 2013;28292:284289p-92.

32 Vagnozzi R, Signoretti S, Tavazzi B, et al. Temporal window of metabolic brain vulnerability to concussion: a pilot $1 \mathrm{H}$-magnetic resonance spectroscopic study in concussed athletes-part III. Neurosurgery 2008;62:1286-95. discussion 1295-1286.

33 Henry LC, Tremblay S, Leclerc S, et al. Metabolic changes in concussed American football players during the acute and chronic post-injury phases. BMC Neurol 2011;11:105.
34 Sikoglu EM, Liso Navarro AA, Czerniak SM, et al. Effects of recent concussion on brain bioenergetics: a Phosphorus-31 magnetic resonance spectroscopy study. Cogn Behav Neurol 2015;28:181-7

35 Chamard E, Henry L, Boulanger Y, et al. A follow-up study of neurometabolic alterations in female concussed athletes. J Neurotrauma 2014;31:339-45.

36 Chamard E, Théoret H, Skopelia EN, et al. A prospective study of physician-observed concussion during a varsity university hockey season: metabolic changes in ice hockey players. part 4 of 4. Neurosurg Focus 2012;33:E4-7.

37 Maugans TA, Farley C, Altaye M, et al. Pediatric sports-related concussion produces cerebral blood flow alterations. Pediatrics 2012;129:28-37.

38 Borich M, Makan N, Boyd L, et al. Combining Whole-Brain Voxel-Wise analysis with In Vivo Tractography of Diffusion Behavior after Sports-Related Concussion in Adolescents: A Preliminary Report. J Neurotrauma 2013:30:1243-9.

39 Chamard $\mathrm{E}$, Lefebvre $\mathrm{G}$, Lassonde $\mathrm{M}$, et al. Long-Term abnormalities in the corpus callosum of female concussed Athletes. J Neurotrauma 2016:33:1220-6.

40 Henry LC, Tremblay J, Tremblay S, et al. Acute and chronic changes in diffusivity measures after sports concussion. J Neurotrauma 2011;28:2049-59.

41 Meier TB, Bergamino M, Bellgowan PSF, et al. Longitudinal assessment of white matter abnormalities following sports-related concussion. Hum Brain Mapp 2016:37:833-45

42 Pasternak O, Koerte IK, Bouix S, et al. Hockey concussion education project, part 2. microstructural white matter alterations in acutely concussed ice hockey players: a longitudinal free-water MRI study. J Neurosurg 2014;120:873-81.

43 Sasaki T, Pasternak 0, Mayinger $M$, et al. Hockey concussion education project, part 3. white matter microstructure in ice hockey players with a history of concussion: a diffusion tensor imaging study. J Neurosurg 2014;120:882-90.

44 Virji-Babul N, Borich MR, Makan N, et al. Diffusion tensor imaging of Sports-Related concussion in adolescents. Pediatr Neurol 2013:48:24-9.

45 Murugavel M, Cubon V, Putukian M, et al. A longitudinal diffusion tensor imaging study assessing white matter fiber tracts after sports-related concussion. $J$ Neurotrauma 2014;31:1860-71.

46 Zhu DC, Covassin T, Nogle S, et al. A potential biomarker in Sports-Related concussion: brain functional connectivity alteration of the Default-Mode network measured with longitudinal Resting-State fMRI over thirty days. J Neurotrauma 2015;32:327-41.

47 Dettwiler A, Murugavel M, Putukian M, et al. Persistent differences in patterns of brain activation after sports-related concussion: a longitudinal functional magnetic resonance imaging study. J Neurotrauma 2014:31:180-8.

48 Zhang K, Johnson B, Pennell D, et al. Are functional deficits in concussed individuals consistent with white matter structural alterations: combined FMRI \& DTI study. Exp Brain Res 2010;204:57-70.

49 Chen JK, Johnston KM, Collie A, et al. A validation of the post concussion symptom scale in the assessment of complex concussion using cognitive testing and functional MRI. J Neurol Neurosurg Psychiatry 2007;78:1231-8.

50 Chen JK, Johnston KM, Petrides M, et al. Neural substrates of symptoms of depression following concussion in male Athletes with persisting postconcussion symptoms. Arch Gen Psychiatry 2008;65:81-9.

51 Keightley ML, Saluja RS, Chen JK, et al. A functional magnetic resonance imaging study of working memory in youth after sports-related concussion: is it still working? J Neurotrauma 2014;31:437-51.

52 Sinopoli KJ, Chen JK, Wells G, et al. Imaging "brain strain" in youth athletes with mild traumatic brain injury during dual-task performance. J Neurotrauma 2014:31:1843-59.

53 Slobounov SM, Zhang K, Pennell D, et al. Functional abnormalities in normally appearing Athletes following mild traumatic brain injury: a functional MRI study. Exp Brain Res 2010:202:341-54.

54 Johnson B, Zhang K, Hallett M, et al. Functional neuroimaging of acute oculomoto deficits in concussed Athletes. Brain Imaging Behav 2015:9:564-73.

55 Borich M, Babul A-N, Yuan PH, et al. Alterations in Resting-State brain networks in concussed adolescent Athletes. J Neurotrauma 2015:32:265-71.

56 Johnson B, Zhang K, Gay M, et al. Alteration of brain default network in subacute phase of injury in concussed individuals: resting-state $\mathrm{fMRI}$ study. Neuroimage 2012:59:511-8.

57 Militana AR, Donahue MJ, Sills AK, et al. Alterations in default-mode network connectivity may be influenced by cerebrovascular changes within 1 week of sports related concussion in college varsity athletes: a pilot study. Brain Imaging Behav 2016:10:559-68.

58 Czerniak SM, Sikoglu EM, Liso Navarro AA, et al. A resting state functional magnetic resonance imaging study of concussion in collegiate Athletes. Brain Imaging Behav 2015;9:323-32

59 Meier TB, Bellgowan PS, Mayer AR. Longitudinal assessment of local and global functional connectivity following sports-related concussion. Brain Imaging Behav 2016.

60 Slobounov SM, Gay M, Zhang K, et al. Alteration of brain functional network at rest and in response to YMCA physical stress test in concussed Athletes: rsfmri study. Neuroimage 2011:55:1716-27.

61 Cao C, Slobounov S. Alteration of cortical functional connectivity as a result of traumatic brain injury revealed by graph theory, ICA, and sLORETA analyses of EEG signals. IEEE Trans Neural Syst Rehabil Eng 2010;18:11-19. 
62 Cao C, Slobounov S. Application of a novel measure of EEG non-stationarity as 'Shannon- entropy of the peak frequency shifting' for detecting residual abnormalities in concussed individuals. Clin Neurophysio/ 2011;122:1314-21.

63 Slobounov S, Cao C, Sebastianelli W. Differential effect of first versus second concussive episodes on wavelet information quality of EEG. Clin Neurophysiol 2009; 120:862-7.

64 Slobounov S, Sebastianelli W, Hallett M. Residual brain dysfunction observed one year post-mild traumatic brain injury: combined EEG and balance study. Clin Neurophysiol 2012;123:1755-61.

65 Prichep LS, McCrea M, Barr W, et al. Time course of clinical and electrophysiological recovery after sport-related concussion. J Head Trauma Rehabil 2013;28:266-73.

66 Meier TB, Bellgowan PS, Singh R, et al. Recovery of cerebral blood flow following sports-related concussion. JAMA Neurol 2015;72:530-8.

67 Len TK, Neary JP, Asmundson GJ, et al. Serial monitoring of CO2 reactivity following sport concussion using hypocapnia and hypercapnia. Brain Inj 2013;27:346-53.

68 Len TK, Neary JP, Asmundson GJ, et al. Cerebrovascular reactivity impairment after sport-induced concussion. Med Sci Sports Exerc 2011;43:2241-8.

69 Mutch WA, Ellis MJ, Ryner LN, et al. Longitudinal brain magnetic resonance imaging CO2 stress testing in individual adolescent Sports-Related concussion patients: A Pilot Study. Front Neurol 2016;7:107.

70 Dambinova SA, Shikuev AV, Weissman JD, et al. AMPAR peptide values in blood of nonathletes and club sport Athletes with concussions. Mil Med 2013:178:285-90.

71 Kiechle K, Bazarian JJ, Merchant-Borna K, et al. Subject-specific increases in serum S-100B distinguish sports-related concussion from sports-related exertion. PLoS One 2014;9:e84977

72 Shahim $\mathrm{P}$, Tegner Y, Wilson DH, et al. Blood biomarkers for brain injury in concussed professional ice hockey players. JAMA Neuro/ 2014;71:684-92.

73 Bouvier D, Duret T, Abbot M, et al. Utility of S100B serum level for the determination of concussion in male rugby players. Sports Med 2016.

74 Shahim P, Mattsson N, Macy EM, et al. Serum visinin-like protein-1 in concussed professional ice hockey players. Brain Inj 2015;29(7-8):872-6.

75 Oliver J, Abbas K, Lightfoot JT, et al. Comparison of neurocognitive testing and the measurement of marinobufagenin in mild traumatic brain injury: a preliminary report. $J$ Exp Neurosci 2015;9:67-72.

76 Pham N, Akonasu H, Shishkin R, et al. Plasma soluble prion protein, a potential biomarker for sport-related concussions: a pilot study. PLoS One 2015;10:e0117286.

77 Schulte S, Rasmussen NN, McBeth JW, et al. Utilization of the clinical laboratory for the implementation of concussion biomarkers in collegiate football and the necessity of personalized and predictive athlete specific reference intervals. EPMA J 2015;7:1.

78 Siman R, Shahim P, Tegner Y, et al. Serum SNTF increases in concussed professional ice hockey players and relates to the severity of postconcussion symptoms. J Neurotrauma 2015:32:1294-300.

79 Shahim $P$, Linemann $T$, Inekci $D$, et al. Serum tau fragments predict return to play in concussed professional ice hockey players. J Neurotrauma 2016:33:1995-9.

80 Daley M, Dekaban G, Bartha R, et al. Metabolomics profiling of concussion in adolescent male hockey players: a novel diagnostic method. Metabolomics 2016;12

81 Shahim P, Tegner Y, Gustafsson B, et al. Neurochemical aftermath of repetitive mild traumatic brain injury. JAMA Neurol 2016;73:1308-15.

82 Hutchison MG, Mainwaring L, Senthinathan A, et al. Psychological and physiological markers of stress in concussed Athletes across recovery milestones. J Head Trauma Rehabil 2016:1

83 Singh R, Savitz J, Teague TK, et al. Mood symptoms correlate with kynurenine pathway metabolites following sports-related concussion. J Neurol Neurosurg Psychiatry 2016:87:670-5.

84 La Fountaine MF, Toda M, Testa A, et al. Suppression of serum prolactin levels after sports concussion with prompt resolution upon independent clinical assessment to permit Return-to-Play. J Neurotrauma 2016;33:904-6.

85 Gill J, Merchant-Borna K, Lee H, et al. Sports-Related concussion results in differential expression of nuclear Factor-kappaB pathway genes in peripheral blood during the acute and subacute periods. J Head Trauma Rehabil 2015.

86 Merchant-Borna K, Lee H, Wang D, et al. Genome-Wide changes in peripheral gene expression following Sports-Related concussion. J Neurotrauma 2016;33:1576-85.

87 McDevitt J, Tierney RT, Phillips J, et al. Association between GRIN2A promoter polymorphism and recovery from concussion. Brain Inj 2015;29(13-14):1674-81.

88 Merritt VC, Arnett PA. Apolipoprotein E (APOE) $\epsilon 4$ allele is associated with increased symptom reporting following sports concussion. I Int Neuropsychol Soc 2016;22:89-94.

89 Merritt VC, Ukueberuwa DM, Arnett PA. Relationship between the apolipoprotein E gene and headache following sports-related concussion. J Clin Exp Neuropsychol 2016:38:941-9.
90 Madura SA, McDevitt JK, Tierney RT, et al. Genetic variation in SLC17A7 promoter associated with response to sport-related concussions. Brain Inj 2016;30:1-6.

91 Gosselin N, Thériault M, Leclerc S, et al. Neurophysiological anomalies in symptomatic and asymptomatic concussed Athletes. Neurosurgery 2006;58:1151-61. discussion 1151-1161.

92 Livingston SC, Saliba EN, Goodkin HP, et al. A preliminary investigation of motor evoked potential abnormalities following sport-related concussion. Brain Inj 2010:24:904-13.

93 Pardini JE, Pardini DA, Becker JT, et al. Postconcussive symptoms are associated with compensatory cortical recruitment during a working memory task. Neurosurgery 2010:67:1020-8. discussion 1027-1028.

94 Slobounov S, Sebastianelli W, Newell KM. Incorporating virtual reality graphics with brain imaging for assessment of sport-related concussions. Conf Proc IEEE Eng Med Biol Soc 2011;2011:1383-6.

95 Baillargeon A, Lassonde M, Leclerc S, et al. Neuropsychological and neurophysiological assessment of sport concussion in children, adolescents and adults. Brain Inj 2012;26:211-20.

96 Barr WB, Prichep LS, Chabot R, et al. Measuring brain electrical activity to track recovery from sport-related concussion. Brain Inj 2012;26:58-66.

97 Breedlove EL, Robinson M, Talavage TM, et al. Biomechanical correlates of symptomatic and asymptomatic neurophysiological impairment in high school football. J Biomech 2012:45:1265-72.

98 Livingston SC, Goodkin HP, Hertel JN, et al. Differential rates of recovery after acute sport-related concussion: electrophysiologic, symptomatic, and neurocognitive indices. J Clin Neurophysio/ 2012;29:23-32.

99 McAllister TW, Ford JC, Ji S, et al. Maximum principal strain and strain rate associated with concussion diagnosis correlates with changes in corpus callosum white matter indices. Ann Biomed Eng 2012:40:127-40.

100 Zhang K, Johnson B, Gay M, et al. Default mode network in concussed individuals in response to the YMCA physical stress test. J Neurotrauma 2012;29:756-65.

101 Hammeke TA, McCrea M, Coats SM, et al. Acute and subacute changes in neural activation during the recovery from sport-related concussion. J Int Neuropsychol Soc 2013:19:863-72.

102 Helmer KG, Pasternak O, Fredman E, et al. Hockey concussion education project, part 1. Susceptibility-weighted imaging study in male and female ice hockey players over a single season. J Neurosurg 2014;120:864-72.

103 Jing M, McGinnity TM, Coleman S, et al. Temporal changes of diffusion patterns in mild traumatic brain injury via group-based semi-blind source separation. IEEE J Biomed Health Inform 2015;19:1459-71.

104 Kontos AP, Huppert TJ, Beluk NH, et al. Brain activation during neurocognitive testing using functional near-infrared spectroscopy in patients following concussion compared to healthy controls. Brain Imaging Behav 2014;8:621-34.

105 Powers KC, Cinelli ME, Kalmar JM. Cortical hypoexcitability persists beyond the symptomatic phase of a concussion. Brain Inj 2014;28:465-71.

106 Teel EF, Ray WJ, Geronimo AM, et al. Residual alterations of brain electrical activity in clinically asymptomatic concussed individuals: an EEG study. Clin Neurophysiol 2014; 125:703-7.

107 Virji-Babul N, Hilderman CG, Makan N, et al. Changes in functional brain networks following sports-related concussion in adolescents. J Neurotrauma 2014:31:1914-9.

108 Balkan 0, Virji-Babul N, Miyakoshi M, et al. Source-domain spectral EEG analysis of sports-related concussion via measure projection analysis. Conf Proc IEEE Eng Med Biol Soc 2015:2015:4053-6.

109 Gay M, Ray W, Johnson B, et al. Feasibility of EEG measures in conjunction with light exercise for Return-to-Play evaluation after Sports-Related concussion. Dev Neuropsychol 2015;40:248-53

110 Yuan W, Wade SL, Babcock L. Structural connectivity abnormality in children with acute mild traumatic brain injury using graph theoretical analysis. Hum Brain Mapp 2015:36:779-92.

111 Broglio SP, Rettmann A, Greer J, et al. Investigating a novel measure of brain networking following sports concussion. Int J Sports Med 2016;37:714-22.

112 Jarrett M, Tam R, Hernández-Torres E, et al. A prospective pilot investigation of brain volume, white matter hyperintensities, and hemorrhagic lesions after mild traumatic brain injury. Front Neurol 2016;7:11.

113 Kontos AP, Reches A, Elbin RJ, et al. Preliminary evidence of reduced brain network activation in patients with post-traumatic migraine following concussion. Brain Imaging Behav 2016;10:594-603.

114 Wright AD, Jarrett M, Vavasour I, et al. Myelin water fraction is transiently reduced after a single mild traumatic brain injury--A prospective cohort study in collegiate hockey players. PLoS One 2016:11:e0150215. 